\title{
sciendo
}

Research Article

C) 2019 Kang et.al..

This is an open access article licensed under the Creative Commons Attribution-NonCommercial-NoDerivs License (http://creativecommons.org/licenses/by-nc-nd/3.0/).

\section{Influencing Factors of Cross-cultural Adaptation Process of Chinese Students Studying in the Upper Northern Thai Universities}

Sun Kang

PhD Candidate, School of Administrative Studies, Maejo University, Chiang Mai, Thailand

Assist. Prof. Dr. Pradtana Yossuck

Assoc. Prof. Dr. Chalermchai Panyadee

Assist. Prof. Dr. Bongkochmas Ek-lem

School of Administrative Studies, Maejo University, Chiang Mai, Thailand

Doi: 10.2478/mjss-2019-0007

\section{Abstract}

With the development of China's 'One Belt and One Road'(OBOR) Initiative, many Chinese students have chosen Thai universities for foreign study in recent years. As usual, problems of cross-cultural adaptation becoming the primary issues they encounter during their stay in Thailand. Based on a survey of 314 Chinese undergraduates studying at eight universities in the upper northern region of Thailand, this study analyzed the influencing factors of the cross-cultural adaptation process of these Chinese students. It tested the Young Yun Kim's structure model, which contains six dimensions of determining aspects on international students' cross-cultural adaptation process. A quantitative research method was applied in this article by using a structured questionnaire as a tool to collect primary data. The data analysis was conducted by using Pearson's Correlation Coefficient and Multiple Regressions. The findings indicated that five dimensions, i.e., Communication Competence (CC), Host Social Communication (HSC), Intercultural Transformation (IT), Environment (EN), and Predisposition (PR) are significant determining aspects for the cross-cultural adaptation process of Chinese students. Furthermore, nine influencing factors out of these five dimensions had significant positive impacts on the cross-cultural adaptation process. Therefore they are considered as the main influencing factors.

Keywords: Cross-culture, Adaptation Process, Chinese Students, Thai Universities, Overseas Study

\section{Introduction}

\subsection{Background}

Under the framework of the $\mathrm{OBOR}^{1}$ Initiative, China announced to intensify all-round cultural and educational cooperation with the countries along the routes and nodes of OBOR. In July 2016,

\footnotetext{
1 "One Belt and One Road Initiative" (OBOR in abbreviation) was presented by China president Xi Jinping at Nazarbayev University of Kazakhstan and Indonesian Parliament in the year 2013 respectively. The "One Belt" refers to the Silk Road Economic Belt, and "One Road" refers to 21st Century Maritime Silk Road. It became China's biggest development strategy and foreign policy in the following years.
} 
Ministry of Education of China issued an educational cooperative document, i.e. Educational Actions on Promoting 'One Belt and One Road' Construction (MOE, P.R. China. July 13 ${ }^{\text {th }}, 2016$ ), the implementation of this official document has caused China to strengthen educational cooperation with OBOR countries, and the number of Chinese students who pursue their university degree in the OBOR countries has greatly increased in recent years.

The ASEAN region which has close connection with China is gradually becoming one of the "hot" destinations for Chinese students studying for higher education. A report from Renmin Daily showed that the number of exchange students between ASEAN countries and China has reached 80,000 in 2015 (with Chinese students going to ASEAN accounting for $60 \%$ ), and according to ASEAN-CHINA education exchange plan, both sides will send over 100,000 overseas students for educational exchange by 2020 . Meanwhile, it is cleared that some countries in ASEAN have claimed their readiness to be center of education in this region. "A number of Southeast Asian countries including Singapore, Malaysia, Vietnam and Thailand have declared that they intend to become higher education hubs in the region. At the same time, Thailand has set the goal of developing into a Southeast Asia hub of education, training, and international conferences and seminars by the year 2018" (Narin Jareonsubphayanot 2015). Due to contribution of these "push" and "pull" forces, more and more Chinese students have chosen Thai universities as their overseas study destination. According to a statistics by Thailand's Office of Higher Education Commission (OHEC), there were 18,814 international students studying in 155 higher educational institutions of Thailand in 2015. Of these about three-fourths are students from China.

As Chinese students are, a majority group, and the main source of international students in Thailand, thus, it seems necessary to learn about their situation and life of study at Thai universities. Moreover, it is vital to understand the cross-cultural adaptation process of Chinese students, because they are learning in a foreign environment.

\subsection{Significance of the Problem}

Studying in a different country can be an exciting and challenging experience for international students, however they must experience many adjustment problems, particularly those relating to academic, socio-cultural and psychological adjustment (Ward \& Kenney 1993). It is evident that international students encounter various obstacles while studying in a different cultural environment. Although many Chinese students at Thai universities have great success, other Chinese students have encountered difficulties while they studied at Thai universities. Ma Dandan (2016) indicated that Chinese students encountered many difficulties related to daily life, academic and communication while they were studying at universities in Thailand. Other literature from both abroad and China has also showed that international students do experience cross-cultural problems. Overseas students report more social difficulty than host students do (Furnham and Bochne, 1982). Li and Jacquic Campbell (2006)'s research showed that many Asian students had to work very hard to adapt to the academic life of the university where they studied, they experienced many difficulties deriving from lack of knowledge of academic norms and conventions, insufficient learning support, unfamiliar teaching methods, and cultural differences in classroom interactions (Li \& Campbell, 2006).

In general, having international students benefits the host country and its educational system in many ways. However, to study abroad causes foreign students both academic and daily life struggles. International educational industry is growing with intense competition, in order to attract more Chinese students to study at Thai universities, it is particular important to understand the life changes (crosscultural adaptation process) of this target group. In addition, Understanding the factors which influence the process of cross-cultural adaptation for Chinese students benefits not only the host institutes but also the students and their family, it helps Chinese students who currently studying at Thai universities to well adapt to host environment and to win better academic achievements.

\subsection{Objectives}

(1) To investigate the determining aspects and its relationships on cross-cultural adaptation process 
of the Chinese students.

(2) To identify the main influencing factors which have significant positive impacts on Chinese students' cross-cultural adaptation process during their period of study at the upper northern Thai universities;

(3) To provide recommendations for Chinese students in terms of improving their school life for a better cross-cultural adaptation, and provide suggestions for Thai universities to adjust their educational program for recruiting more Chinese students.

\section{Literature Review}

According to Young Yun Kim, the term cross-cultural adaptation is defined as " the dynamic process by which individuals, upon relocating to new, unfamiliar, or changed cultural environment, establish or reestablish and maintain relatively stable, reciprocal, and functional relationships with those environments" (Kim,1991,2001,2005). In her integrative theory of communication and crosscultural adaptation, Kim put forward two models: the first is Process Model: it portrayed the process of cross-cultural adaptation as a three-pronged tress-adaptation-growth dynamic. The stressadaptation-growth dynamic does not develop in a smooth, steady, and linear direction, but rather in a dialectic, cyclic, and continual 'draw-back-to-leap' pattern, while the state of stress can produce a state of imbalance, misfit, uncertainty, confusion, and anxiety; The second is Structure Model: it illuminated the process of cross-cultural adaptation by six dimensions (determining aspects), which were named as: Communication Competence (CC), Host Social Communication (HSC), Ethnic Social Communication (ESC), Intercultural Transformation (IT), Environment (EN), and Predisposition (PR) (Kim, YY, 2001).

This study tried to apply and test Kim's structure model (six dimensions) for the explaining of the cross-cultural adaptation process of Chinese students studying in the upper northern Thai universities. The purpose of Kim's putting forward the integrative theory on communication and cross-cultural adaptation is to answer two main questions: (1) what is the essential nature of the cross-cultural adaptation process? And (2) what are factors contribute to sojourners' success in the cross-cultural adaptation process? These two questions are closely related to the research objectives, therefore it is very concerned by the researcher.

There are other theories on cross-cultural adaptation process such as Oberg (1960) 's "Culture-Shock" model, Lysgaard(1995) 's "U-Curve" model, and Gullahorn \& Gullahorn (1963) "Wshape curve" model etc. These were not explained further in this article.

\section{Research Methodology}

\subsection{Conceptual Framework of the Study}

The conceptual framework of this study was based on Y. Y. Kim's integrative theory on crosscultural adaptation which was showed as Table 1, and the following two hypotheses were formulated:

H1: Six determining aspects (Communication Competence, Host Social Communication, Ethnic Social Communication, Intercultural Transformation, Environment, and Predisposition) have significant positive relationships with Chinese students' cross-cultural adaptation process;

H2: Sixty factors out of the six determining aspects will be significant predictors of crosscultural adaptation process of the Chinese students, and all sixty factors are considered as main influencing factors of the process. 
Table 1: The Conceptual Framework of the Study

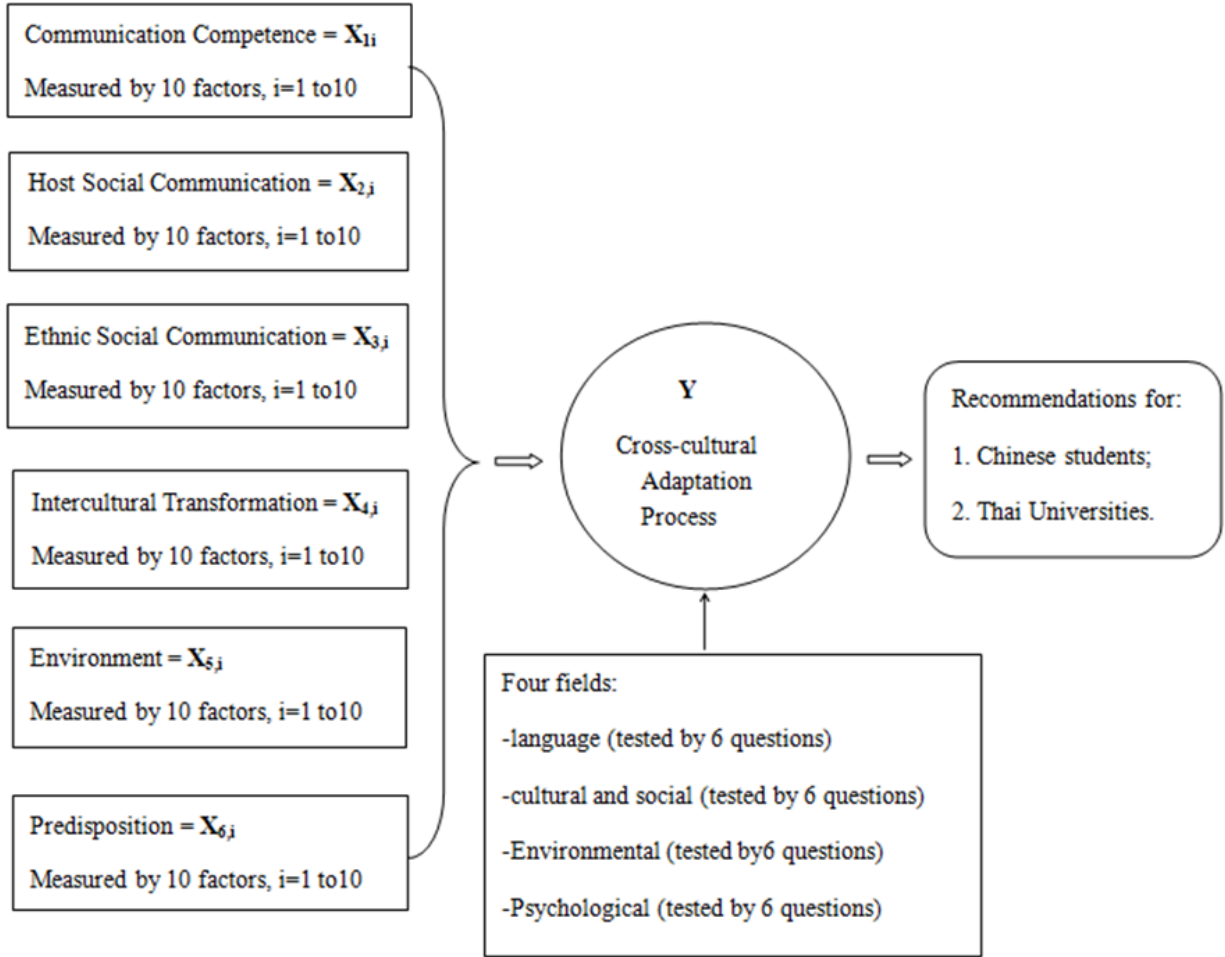

\subsection{Methods}

In order to answer questions of the first and the second objectives, a structured questionnaire was designed, it consists two parts: The first part includes 15 questions about respondents' socialdemographic, and the second part includes 84 questions for test the influencing factors. The answers were multiple choice in 5-point Likert Scale, ranging from Strongly Agree (5) to Strongly Disagree (1).

This study mainly focus on quantitative method, therefore correlation and multiple regression were the analysis tools, which was applied to find out the relationship between independent variables (influencing factors) and the dependent variable (cross-cultural adaptation process).

The multiple regression model was written as below:

$Y=\alpha+\beta_{1} X_{1,1}+\beta_{2} X_{1,2 \ldots}+\beta_{11} X_{2,1}+\beta_{12} X_{2,2 \ldots}+\beta_{21} X_{3,1}+\beta_{22} X_{3,2 \ldots}+\beta_{31} X_{4,1}+\beta_{32} X_{4,2 \ldots}$

$+\beta_{41} X_{5,1}+\beta_{42} X_{5,2 \ldots}+\beta_{51} X_{6,1}+\beta_{52} X_{6,2 \ldots}+\varepsilon$

Where $Y$ is overall cross-cultural adaptation process, and $X_{i, j}, i=1,2,3 \ldots 6, j=1,2,3 \ldots 10$ are influencing factors.

\subsection{Validity and Reliability of Research Instrument}

An Item-Objective Congruence (IOC) test and Cronbach's alpha coefficient test for the questionnaire was conducted respectively before a real field survey, steps as follows:

(1) Five experts independently rated the relevance of each question to the research on the questionnaire by using 4-point Likert-scale (1=irrelevant; 2=weak relevant; 3=relevant; 4=very relevant), and the final score of Item-Content Validity index (I-CVI), and Scale-Content Validity 
Index (S-CVI) was calculated ${ }^{2}$. The overall content validity has been confirmed by S-CVI value = 0.980 .

(2) By using SPSS (19.0) to calculate Cronbach's Alpha of the questionnaire, the researcher obtained result of Cronbach's alpha coefficient $=0$. 950, suggesting that the items have relatively high internal consistency.

\subsection{Sampling Procedure}

There are total thirteen universities located in the upper northern region of Thailand, however only universities with long-term students (over 3 months, whose life changes can be observed) will be counted. Finally, eight universities from the upper northern region of Thailand were selected. ${ }^{4}$ The names of target universities was listed as: (1) Maejo University (MJU); (2) Chiang Mai University(CMU) ;(3) Chiang Mai Rajabhat Universitry (CMRU);(4) Far Eastern University(FEU);(5) Payap University(PYU);(6) Chiang Rai Rajabhat University(CRRU);(7) Mae Fah Luang University(MFU); (8) Lampang Rajabhat University(LPRU).

According to a primary survey, there were 1034 long-term Chinese students studying in these eight upper northern Thai universities (survey period: Nov. 1 to Dec. 30, 2017). By using Taro Yamane (1967)'s formula ${ }^{5}$, the sample size was computed as 289 . Considering these students were scattered at eight different universities, Proportional Stratified Random Sampling (PSRS) method was applied in choosing the sample, the sample proportion for each university will be approximately $28 \%(289 / 1034 \approx 28 \%)$, and the researchers adjusted it to $30 \%(n=314)$ for better handling.

Based on the PSRS method, a total 314 sample respondents, with same proportion (30\%) for each universities, were selected randomly. The sample size of respondents was showed in Table 2.

Table 2: Sample Size of Respondents per Universities

\begin{tabular}{llllr}
\hline Universities & Chiang Mai & Chiang Rai & Lampang & Total (P/s) \\
Rajabhat University (P/s) & CMRU 102/31 & CRRU 209/63 & LPRU 51/16 & $362 / 110$ \\
Public University (P/s) & MUU 81/25 & MFU 212/64 & & $565 / 171$ \\
& CMU 272/82 & & \\
Private University (P/s) & FEU 19/6 & & $107 / 33$ \\
& PYU 88/27 & & \\
\hline Total (P/s) & $562 / 171$ & $421 / 127$ & $51 / 16$ & $1034 / 314$ \\
\hline
\end{tabular}

** $\mathrm{P}$-population number; $\mathrm{s}=$ sample number

${ }^{2}$ I-CVI value $=n / N$ and $S$-CVI value $=\sum_{i=1}^{t}(n) / N^{*} t$, where $n=$ number of experts giving a rating of 3 or 4; $N=$ total number of experts; $t=n u m b e r$ of questions;

${ }^{3} \mathrm{~S}-\mathrm{CVI}$ value range from 0 to 1 , the higher value, the better content validity, usually the researcher accept items which S-CVI value greater than 0.8 .

${ }^{4}$ There are no universities established in Lamphun, Phrae, Nan and Mae Hong Son province, and Phayao University, which is only higher institute in Phayao province, does NOT have long-term Chinese students.

${ }^{5}$ Yamane's formula for determine sample size: $n=N /\left(1+N e^{2}\right)$, where $n=$ required sample size, $N=$ the population size; $E=$ margin error \%, in this case $e=0.05$. 


\section{Analysis and Results}

\subsection{Descriptive Analysis}

The social-demographic characteristics of the respondents were obtained through descriptive analysis, which includes basic information such as sex, age, origin place in China etc.

The results showed that the majority or $235(74.8 \%)$ were female, most of the respondents or $292(93 \%)$ were at the age range from 19 to 22 . Most of students came from Yun Nan $(77.7 \%)$, they are either studying at a bachelor program $(62.1 \%)$ or a joint -exchange program $(33.8 \%)$. Student majoring in Thai language accounting for 181 (57.6\%), and other majors enrollment depends on the international programs offered by the host universities. Although the tuition fee varies among different Thai universities, most of it ranges from 50,000 baht to 200,000 baht per year.

\subsection{Correlation Analysis}

The outputs of SPSS correlation analysis was listed as Table 3. The results indicated that five determining aspects had the significant positive correlation with Chinese students' cross-cultural adaptation process, and it was significant at 0.01 level.

According to Hypothesis 1, all six determining aspects will have positive relationships with Chinese students cross-cultural adaptation process, however the test confirmed that only five of them (CC, HSC, IT, EN,PR) had positive impacts on Chinese students cross-cultural adaptation process. Therefore, the HYPOTHESIS 1 was rejected.

Table 3. Outputs of Pearson's Correlation

\begin{tabular}{|c|c|c|c|c|c|c|c|}
\hline Determining Aspects & 1 & 2 & 3 & 4 & 5 & 6 & 7 \\
\hline (Dimensions) & $\mathrm{X}_{1}(\mathrm{CC})$ & $\mathrm{X}_{2}$ (HSC) & $\mathrm{X}_{3}(\mathrm{ESC})$ & $\mathrm{X}_{4}$ (IT) & $\mathrm{X}_{5}(\mathrm{EN})$ & $\mathrm{X}_{0}(\mathrm{PR})$ & ) $\mathrm{Y}$ \\
\hline \multirow[t]{2}{*}{$\mathrm{X}_{1}(\mathrm{CC})$} & 1 & $.629 * *$ & .061 & $.490 * *$ & $.426 * *$ & $.518 * *$ & $.549 * *$ \\
\hline & Sig. & .000 & .280 & .000 & .000 & .000 & .000 \\
\hline \multirow[t]{2}{*}{$\mathrm{X}_{2}$ (HSC) } & & 1 & .029 & $.536^{* *}$ & $.448 * *$ & $.470^{* *}$ & $.599 * *$ \\
\hline & Sig. & & .610 & .000 & .000 & .000 & .000 \\
\hline \multirow[t]{2}{*}{$\mathrm{X}_{3}(\mathrm{ESC})$} & & & 1 & .092 & $.127^{*}$ & .096 & .060 \\
\hline & Sig. & & & .104 & .024 & .089 & .290 \\
\hline \multirow[t]{2}{*}{$\mathrm{X}_{4}$ (IT) } & & & & 1 & $.623^{* *}$ & $.530 * *$ & $.680^{* *}$ \\
\hline & Sig. & & & & .000 & .000 & .000 \\
\hline \multirow[t]{2}{*}{$\mathrm{X}_{5}(\mathrm{EN})$} & & & & & 1 & $.581^{* *}$ & $662^{* *}$ \\
\hline & Sig. & & & & & .000 & .000 \\
\hline \multirow[t]{2}{*}{$\mathrm{X}_{6}(\mathrm{PR})$} & & & & & & 1 & $.551^{* *}$ \\
\hline & Sig. & & & & & & .000 \\
\hline \multicolumn{3}{|c|}{ Y(Cross-Cultural Adaptation Process) } & & & & & 1 \\
\hline ** Correlation is signific & t the 0.01 les & el (2-tailed); & * Correction & is significa & at the 0.05 & evel (2-tailed). & \\
\hline
\end{tabular}




\subsection{Multiple Regression Analysis}

The Multiple Regression Analysis (MRA) was employed to find out the main influencing factors of Chinese students' cross-cultural adaptation process. The outputs of SPSS MRA model was listed as Table 4. It was showed that only nine factors had significant positive impacts on Chinese students' cross-cultural adaptation process, therefore they were tested and be considered as main influencing factors. Furthermore, MRA model with these nine influencing factors could interpret $67.9 \%$ of the variance in the overall students' cross-cultural adaptation process.

According to Hypothesis 2, all sixty factors will be significant predictors of this process. Therefore, HYPOTHESIS 2 was rejected by the MRA results. The MRA model can be written as: $Y=3.232+0.202 X_{1}+0.143 X_{2}+0.095 X_{3}+0.135 X_{4}+0.120 X_{5}+0.130 X_{6}+0.125 X_{7}+0.114 X_{8}+0.088 X_{9}$ factors.

Where, $Y=$ Chinese students' cross-cultural adaptation process, $X_{1}$ to $X_{9}$ are main influencing

Table 4. Outputs of Multiple Regression Model and Coefficients ( $N=314)$.

MODEL SUMMARY

\begin{tabular}{|c|c|c|c|c|c|c|c|}
\hline \multirow[t]{2}{*}{$\mathbf{R}$} & \multirow{2}{*}{$\begin{array}{c}\text { R Square } \\
.679\end{array}$} & \multirow{2}{*}{$\begin{array}{c}\text { Adjust R Square } \\
\quad .666\end{array}$} & \multicolumn{3}{|c|}{ Std. Error of Estimate } & \multirow{2}{*}{$\begin{array}{c}\text { Overall F } \\
48.920\end{array}$} & \multirow{2}{*}{$\begin{array}{l}\text { Sig. } \\
000^{* * *}\end{array}$} \\
\hline & & & & 7.632 & & & \\
\hline \multicolumn{3}{|l|}{ Variables } & B & Std. Error & Beta & t-value & Sig. (p) \\
\hline \multicolumn{3}{|l|}{ (constant) } & 3.232 & 3.684 & & .887 & .381 \\
\hline \multicolumn{3}{|c|}{$\mathrm{X}_{1}$ : be satisfied with school life. } & 3.120 & .654 & .202 & 4.771 & $.000^{* * *}$ \\
\hline \multicolumn{3}{|c|}{$\mathrm{X}_{2}$ : be fit-in with Thai society. } & 2.766 & .764 & .143 & 3.622 & $.000^{* * *}$ \\
\hline \multicolumn{3}{|c|}{$\mathrm{X}_{3}:$ like Thai people and culture } & 1.609 & .673 & .095 & 2.390 & $.017^{*}$ \\
\hline \multicolumn{3}{|c|}{$\mathrm{X}_{4}$ : international environment of host university } & 2.149 & .589 & .135 & 3.648 & $.000^{* * *}$ \\
\hline \multicolumn{3}{|c|}{$\mathrm{X}_{5}$ : having adaptive personality } & 1.794 & .548 & .120 & 3.277 & $.001^{* *}$ \\
\hline \multicolumn{3}{|c|}{$\mathrm{X}_{6}$ : be fond of hanging out with Thai friends } & 1.670 & .463 & .130 & 3.608 & $.000^{* * *}$ \\
\hline \multicolumn{3}{|c|}{$\mathrm{X}_{7}$ :China social \& economic development impacts } & 2.155 & .600 & .125 & 3.590 & $.000^{* * *}$ \\
\hline \multicolumn{3}{|c|}{$\mathrm{X}_{3}$ : enjoy studying at Thai universities } & 1.881 & .707 & .114 & 2.661 & $.008^{* *}$ \\
\hline \multicolumn{3}{|c|}{$\mathrm{X}_{9}$ : be prepared for the financial aspects } & 1.275 & .508 & .088 & 2.509 & $.013^{*}$ \\
\hline
\end{tabular}

Note: Significant level: $*<0.05, * *<0.01, * * *<0.001$.

\section{Conclusions and Discussions}

\subsection{Which Chinese students come to studying at upper northern region of Thailand? Why?}

From the descriptive analysis we can concluded that students from Yunnan, Guangxi and Sichuan province were the majority $(90.7 \%)$ in the upper northern Thai universities. Furthermore, the number of Yunnan student $(77.7 \%)$ were dominant in each Thai university in the upper northern region. The obvious reason of that is the geographical advantages of these three provinces. Beside this, the Chinese government's educational policies and the increased number of academic linkages between Yunnan universities and Thai universities both contributed to the increasing number of Yunnan students' studying in Thailand. The so-called "push" forces for Yunnan students coming to study at Thailand include: 
(1) The Ministry of Education(MOE) of China signed an MOU with Yunnan Provincial Government for promoting an 'OBOR' Educational Action Plan in the provincial level on Nov 22, 2016, (just a few months after MOE's national level Educational Action Plan), and the implementation of this action plan will provides substantial support for Yunnan students in both financial and policies aspects.

(2) There are twenty-eight universities in Yunnan which teach Thai language. The total number of full-time students of Thai languages and related majors in campus exceeded 50,000 in 2017. In addition, Most of these Yunnan universities established " $2+2$ "or " $3+1$ " joint exchange programs with upper northern Thai universities, that means, all students enrolled in these joint exchange program will transfer to Thai universities for one or two years internship after they have finished the first period of study in China universities.

Other findings of the research on Chinese students' social demographic characteristics includes: Most of Chinese students are in their age period of undergraduate level; About three quarters $(74.8 \%)$ of the Chinese students are female; Approximate $60 \%$ of Chinese students are in Thai language major; Although the tuition and fee vary, most charge from 50,000 bahts to 200,000 bahts per year. Reasons: (1).Thai degree are fully recognized by Chinese government. This provides an opportunity for Chinese students, who failed in GaoKao (China National Matriculation Exam), to pursuit of a degree at Thai universities. (2).Choosing a foreign language (such as Thai) as university major by female Chinese students is thought to benefits one's career. That's also explained the gender ratio of the sample. (3).With the development of China economy, overseas study are easily afforded by many Chinese families.

\subsection{What are the most important factors influencing Chinese students' cross-cultural adaptation process? What are the reasons?}

Base on the results of quantitative analysis and the previous study, the following conclusions can be drawn:

- Five determining aspects had significant positive relations with Chinese students' crosscultural adaptation process, they are CC, HSC, IT, EN and PR. This validates Kim's structure model to a large extent. However, ESC did not show significant positive relations with students cross-cultural adaptation process, because ESC means Chinese students interact and intercommunicate only with Chinese group in host cultural setting (Thai culture), it makes Chinese students feeling happy and helps them be settled down quickly at the beginning of their overseas' study, but it hinders the process of their cross-cultural adaptation in the long run.

- Among sixty influencing factors out of these five aspects, nine were confirmed as main influencing factors. Furthermore, the researcher argued that two internal factors and two external factors are the most important factors influencing Chinese students' cross-cultural adaptation process.

(1) The most important internal factors were: Being satisfied with school life $(\beta=0.202$, $\mathrm{P}=0.000)$, followed by be fit-in with Thai society $(\beta=0.143, \mathrm{P}=0.000)$. Reasons:

Satisfied with the school life definitely means one is well-adapted to the learning environment and to a teaching system and style in the host country. It is an essential factor throughout the whole overseas' study period of Chinese students. Chinese students who are satisfied with their school life showed better adaptation and higher level in academic fields, this outcome also supported by other study: 'it claimed that the importance of teaching quality and the role of lectures including a suitable learning environment are perceived to be the most important variable affecting and generating student satisfaction...' (Paweena Songsathaphorn, 2014).

$\mathrm{Be}$ fit-in with Thai society is key. It could include: becoming accustomed to the environment, the community, and having good interpersonal relationship and so on. It helps Chinese students to settle down and start their life in a Thai universities in a short time. Other research findings also showed that Chinese students did well both in daily and academic life if he or she was fit-in with host society: 'the factors affecting the behavior of 
them (Chinese students) were the friendliness of the people, fundamental infrastructure, beauty of the environment, and safety' (Narin Jareonsubphayanont, 2014).

(2) The most important external factors were: International environment of the host university $(\beta=0.135, P=0.000)$, followed by impacts of China's social and economic development $(\beta=0.125, P=0.000)$. Reasons:

International environment of the host university is the most essential factor of Chinese students studying in Thailand. According to the information obtained by the researcher, international environment of a foreign university is the first consideration for all Chinese families in deciding a foreign study. It confirmed by research point from another scholar: 'the most important pull factor on Chinese students is the reputation of the Thai university, the second is the international environment exciting the students' (An Zhongcheng, 2013).

Impacts of China's social and economic development is a big influence and "push" force for Chinese students' overseas study. Supporting points from U.S scholars is: 'with the emergence of China's middle class, studying abroad became much more prevalent,...These obligations and the growth of China's middle class starting in 2004 are what really skyrocketed international student studying' (Rachel T. Barclay, Mandie Weinandt, Allen C. Barclay 2017). In addition, according to answers by respondents of this study, Chinese student with strong family affiliation and social support don't worry so much about the financial issue, homesickness or the distance issue.

\section{Recommendations}

\section{For Chinese students}

- Choose a Thai university with a major which you are really interested, and work hard on your Thai language. Speaking the host country's language is a key element for a better cross-cultural adaptation. This has been proven by the first-hand experiences of many peer students studying in Thailand.

- Try to learn and understand Thai cultures and society, make friends with Thai people, especially Thai teachers and students.

- Become familiar with Thai higher education system and Thai universities programs or curricula. In addition, make efforts to enhance one's international academic ability for a better school life.

- Be prepared for both financial aspects and psychological aspects before going abroad.

For Thai higher education institutes

- High quality international programs are the most important factor for Thai higher educational institutes in attracting Chinese students. Therefore, Thai universities must concern themselves with quality control of their education system and teachers' qualification. They must try to offer more international programs to meet the needs of Chinese students and their families. In short, Thai university as a service provider should satisfy the "customers" with good educational products.

- Thai universities who recruit Chinese students should pay more attention to improving their international environments and academic related aspects, such as teaching style, curriculum design and so on.

- Orientation sessions for international programs shall be organized before a new semester starts, and a full-time orientation instructor for Chinese students should also be arranged for the duration of their time in the university. It helps Chinese new comers to become better adapted to the host environment in Thai universities and creates good 'word-ofmouth' advertising for the university at the same time.

- To build up partnership with more Chinese universities, and establish more joint exchange programs. The starting point could be to develop short-term internships or language exchange courses and culture experience courses. 


\section{References}

177Liuxue News: Southeast Asian-Next Hot Destination for Chinese Students Studying Abroad, August 19,2014.[Online] Available: http://www.177liuxue.cn/xuexiao/2009-9/47552.html

An Zhongcheng,(2013). Aspects of Globalization in Higher Education: Why Chinese Students Choose to Study in Thailand'. Stamford Journal, 5(1):30-36.

Furnham, A (1988), The Adjustment of Sojourners. In Kim Y. Y., \& Gudykunst. W.B. (Eds.) Theories in Intercultural Communication. Newbury Park: Sage Publication Inc. (1988);

Hongzhi Y. Athapol Ruangkanjanases \& Chennin,C., (2015), Factors Affecting Chinese Students' Decision Making toward Thai Universities. International Journal of Information and Education Technology 5 (3):189195.

Kim. Y.Y., (2005).,Adapting to a New Culture: An Integrative Communication Theory. In Willianm B. Gudykunst. (Eds.) Theorizing about Intercultural Communication.Thousand Oaks, CA: Sage Publications.Inc.

Lysgaard S., (1955), Adjustment in a Foreign Society: Norwegian Fulbright Grantees Visiting the United States. International Social Science Bulletin, 7: 45-51.

Ma Dandan (2016). A Survey and Suggestions on Cross-cultural Adaptation of Chinese Students Studying in Thailand: A Case Study on Qujing Normal University. Asia-Pacific Education.2016(03): 247-248.

Narin Jareonsubphayanont,. (2014). South Asian Studies in Asia from Multidisciplinary Perspective International Conference. (Conference Paper, Kunming,China. Mar, 2014).

Oberg. K., 2000, Culture Shock and the Problem of Adjustment in New Cultural Environments.In. Weaver. G.R. (Eds). Culture. Communication and Conflict: Reading in Intercultural Relations.Boston: Pearson Publishing (pp: 175-176).

Paweena Songsathaphorn, Chenin Chen, Athapol Ruangkanjanases.,(2014). A Study of Factors Influencing Chinese Students' Satisfaction toward Thai Universities. Journal of Economics, Business and Management. 2(2): 105-111.

Rachel T. Barclay, Mandie Weinandt, Allen C. Barclay,. (2017) The Economic Impact of Study Abroad on Chinese Students and China's Gross Domestic Product. Journal of Applied Business and Economics. 19 (4): 30-36.

Renmin Daily: China-ASEAN Education Exchange Enters into Fast Lane, September 20, 2016. [Online]Available: http://news.163.com/16/0920/03/C1CIJ8L500014AED.html.

Ruirong M., \& Yi, L., (2016), Social Support: A Moderator between Cultural Intelligence and Cross-cultural Adaptation of International Students in Chinese Universities. International Forum of Teaching and Studies. 2016(2):32-36.

T. Yamane, Statistics, an Introductory Analysis. $2^{\text {nd }}$ Ed. New York. Harper and Row. 1967;

Veenunkarn Rujiprak., Ward C. \& Kennedy A., 1999, The Measurement of Socio-cultural Adaptation.International Journal of Intercultural Relations. 23 (4):659-677. 